\title{
XXXVIII. On Mr. Heath's criticism of Ferrel's theory of atmospheric currents
}

\section{Frank Waldo}

To cite this article: Frank Waldo (1883) XXXVIII. On Mr. Heath's criticism of Ferrel's theory of atmospheric currents, Philosophical Magazine Series 5, 16:100, 264-267, DOI: $10.1080 / 14786448308627429$

To link to this article: http://dx.doi.org/10.1080/14786448308627429

曲 Published online: 28 Apr 2009.

Submit your article to this journal

Џll Article views: 3

Q View related articles $\asymp$ 
because it would greatly augment the quantity of vapour which would be available for snow.

I shall next examine at considerable length $\mathrm{Mr}$. Alfred $\mathrm{R}$. Wallace's modification of the theory, as given in 'Island Life.'

XXXVIII. On Mr. Heath's Criticism of Ferrel's Theory of Atmospheric Currents. By Frank WaLdo*.

$\mathrm{T} \mathrm{T}$ is not astonishing that $\mathrm{Mr}$. Heath should not bave a cor1 rect idea of the Theory of Atmospheric Currents accepted by the meteorologists of today; but he was rather hasty in writing the criticisms on Mr. Ferrel's paper which have just appeared (in the July number of this Journal).

I should do nothing more than refer the critic to papers from which he could obtain information, if it were not that an answer to his remarks is called for, not at all to defend Ferrel, because that is unnecessary, but to bring this matter a little more prominently before those who have read the criticism referrsd to, and who, if they accept it, will form an incorrect notion of the theory of atmospheric currents.

In the first place the critic seems to be almost totally unacquainted with the literature of the subject. It is true that he has apparently read Ferrel's first mathematical paper, and some minor papers in 'Nature ;' but he makes no reference to the other papers (more tban sixty) on this topic which have appeared within the last twenty-five years.

The whole subject is one that has been much neglected in England; and, apart from the papers in 'Nature,' an article published by Mr. Daniel Vaughan of Cincinnati (U.S.) in the British-Association Report for 1859 , and an article by Professor Everett, I know of no purely English writings which can be called at all important on the new dynamical meteorology.

I will first take up some of the points touched upon by the critic, and make a few references to the literature.

Dr. Haughton, as quoted on page 13, renders only due credit to Ferrel when he says that Ferrel has given a solution, which is in general satisfactory, of the problem of air-currents in his important memoir. This memoir is justly considered the first of the series of papers which followed, in which the atmospheric movements are deduced dynamically; and it is recognized as the most important paper in the earlier history of the new meteorology-new as opposed to the Dovian.

Mr. Heath says (pp. 14-15):- "A mass situated anywhere near the surface, but unconnected with it and unresisted by the air. if put in motion, will begin to move in fixed

* Communicated by the Author. 
space, in a straight line, in a direction and with a velocity compounded of the velocity it had in common with the surface at that place and that of the impulse given to it, in accordance with the principle of the Parallelogram of Velocities, and will be drawn out of that line only downwards, by the force of gravity at the centre of the earth ; and therefore it will never leave the plane of the great circle, fixed in space, which comprises the original direction and this centre." This refers to absolute motion, while the question is one of relative; it will be spoken of further on. However, that this absolute motion is not in the least contradictory to the application of the principle of the preservation of areas as carried out by Ferrel and others and as questioned by Mr. Heath, is proven by Dr. A. Sprung in an article, "Zur Anwendung des Princips der Flächen in der Meteorologie," Oesterr. Zeitschrift für Meteorologie, Band xvi. page 62 .

On page 15 he remarks that Sir John Herschel, in bis 'Meteorology,' does not mislead his readers as Ferrel does. It may be bere remarked that, in the book referred to, Herschel did not give the true theory of the winds as at present accepted. Ferrel was right in speaking of the wrong teaching of the text-books, because it is only a few years since the true explanation was first given in any of them, and even now those in which it is found can be counted on the fingers of one hand.

The "force" which is described on page 15 as incomprehensible is explained in Poisson's paper on projectiles, "Mémoire sur le mouvement des projectiles dans l'air, en ayant égard à la rotation de la terre," lu à l'Académie des Sciences, le 14 novembre 1837, Journal de l'Ecole Polytechnique, cahier xxvi. There is also a discussion on the subject in the Comptes Rendus, tome xlix. \&c., \&c. ; and Poisson's paper is mentioned in Routh's 'Rigid Dynamics' (3rd edition), 1877, p. 218.

In regard to Ferrel's criticisms of Colding, he was right in saying that Colding did not take into account one component of the effect of the earth's rotation.

As to Ferrel and Everett having jointly discovered this component, there has never, to my knowledge, been such a clain made. It was discovered many years previously, but was rediscovered by Ferrel independently.

In regard to the two points brought out on page 18 -first, the application of the principle of the conservation of areas, and, secondly, the path of a body on the earth's surface-Mr. Heath is in error in his criticism. As to the first point, this is not the first time that the application of this theorem has been questioned. Dr. Thiesen employs it in an article "Uober 
Bewegungen auf der Erdoberfläche," pages 203-206, Band xiv. of the Oesterreichischen Zeitschrift für Meteorologie, and, on being criticised for doing so, replies, "the area principle is always applicable in a determined plane, if the projection of the forces acting in this plane has no momentum" (see page 88, Band $\mathrm{xr}$. of the same Journal). Also, page 89, "In the present case, in which the earth is regarded as a rotating body, the attracting force as well as the predominating pressure force on the earth's surface lies in the meridian, and consequently has in the equatorial plane no momentum of rotation in relation to the earth's axis."

On page 40 of Kirchhoff's Mechanik (2nd edition), as well as in Schell's Theorie der Bewegung und der Kräfte (2nd edition), pages 351-354, is found the theorem of the conservation of areas and the cases to which it can be applied; and here we find the theorem employed by Thiesen. This proves conclusively that Ferrel is correct in using it.

With respect to the second point, on page 209 of the third edition of Routh's 'Dynamics' we find the following theorem:- " In finding the motion of a particle of mass $m$ with reference to any moving axes, we may treat the axes as if they were fixed in space, provided we regard the particle as acted on, in addition to the impressed forces, by two forces:(1) a force equal and opposite to that which would constrain the particle to remain fixed to the moving axes, and which is measured by $m f$, where $f$ is the reversed acceleration of the point of moving space occupied by the particle; (2) a force perpendicular to both the direction of relative motion of the particle and to the central axis or axis of rotation of the moving axes, and which is measured by $2 m \mathrm{~V} \Omega \sin \theta$, where $\mathrm{V}$ is the relative velocity of the particle, $\Omega$ the resultant angular velocity of the moring axes, and $\theta$ the angle between the direction of the volocity and the axis of rotation."

It is a question of relative motion that is being considered; and it is evident, as Routh remarks on page 213 , that " the motion of a body on the surface of the earth is not exactly the same as if the earth were at rest."

A casual reader might see part of Ferrel's paper in the same light as $\mathrm{Mr}$. Heath ; but we must remember that it is to be taken for the most part as a qualitative and not a quantitative investigation.

Although not in formula, yet in words the equation of continuity is taken into account.

On pages 18 to 23 we find a more detailed criticism of Ferrel's paper.

That Ferrel's results were somewhat peculiar is to be ad- 
mitted; and it was perbaps this peculiarity that kept them so long unrecognized; but careful study has led to their acceptance by the foremost meteorologists. He could not hope to solve the complex problem as it really exists, and was obliged to make his solution very general.

On pp. 386-391, Band xiv. of the Oesterr. Zeitsch. für Meteorologie is given a review of the first part of Ferrel's elaboration, mentioned below, of his early paper; pp. 161-175 and 276-283 of the xvii. Band of the same Journal contain a review of the second part; and the whole was again reviewed in 'Nature' last year.

It appears as though Ferrel's critic had written his article from the point of view of a student of Laplace and Airy, and had not examined the more modern text-books on mechanies to see if Ferrel's reasoning was admissible.

It is hoped that instead of heeding the warning that has been sounded against Ferrel, the readers of this Journal will read the elaborations of his first paper, given as Appendices to the U.S. Coast-Survey Reports for 1875 and 1878 .

Mr. Heath's paper will have one good effect, I hope; and that is, to interest some of the English matlematicians and physicists in this subject.

XXXIX. On the Equation to the Secular Inequalities in the Planetary Theory. By J. J. Sylvester, F.R.S.*

A VERY long time ago I gave, in this Magazine, a proof A of the reality of the roots in the above equation, in which I employed a certain property of the square of a symmetrical matrix which was left without demonstration. I will now state a more general theorem concerning the product of any two matrices of which that theorem is a particular case. In what follows it is of course to be understood that the product of two matrices means the matrix corresponding to the combination of two substitutions which those matrices represent.

It will be convenient to introduce here a notion (which plays a conspicuous part in my new theory of multiple algebra), viz. that of the latent roots of a matrix-latent in a somewhat similar sense as vapour may be said to be latent in water or smoke in a tobacco-leaf. If from each term in the diagonal of a given matrix, $\lambda$ be subtracted, the determinant to the matrix so modified will be a rational integer function of $\lambda$; the roots of that function are the latent roots of the matrix; and there results the important theorem that the latent roots of

* Communicated by the Author. 